\title{
FITOSSOCIOLOGIA DE UMA ÁREA DE CERRADO DENSO NA RECOR-IBGE, BRASÍLIA-DF
}

Recebido em 24/02/2000. Aceito em 03/04/2002.

\author{
Luciana A. Z. Andrade ${ }^{1}$ \\ Jeanine Maria Felfili ${ }^{2}$ \\ Luciano Violatti ${ }^{3}$
}

\begin{abstract}
RESUMO - (Fitossociologia de uma área de cerrado denso na RECOR-IBGE, Brasília-DF). Foi amostrada uma área de 10ha de cerrado denso da RECOR-IBGE, Brasília-DF. Nesta foram estabelecidas parcelas experimentais de um projeto para o estudo do efeito do fogo na vegetação do cerrado com um delineamento em blocos casualizados. Este levantamento foi efetuado antes da aplicação dos tratamentos visando conhecer a composição florística e estrutura da vegetação original. Foram incluídos todos os indivíduos lenhosos e aqueles não-lenhosos pertencentes à família Velloziaceae, com diâmetro mínimo de $5 \mathrm{~cm}$, presentes em cinco parcelas de $1000 \mathrm{~m}^{2}$. Foram medidas as alturas e os diâmetros a $30 \mathrm{~cm}$ do solo de cada indivíduo. Ao todo foram amostrados 982 indivíduos, pertencentes a 63 espécies e a 34 famílias. Cerca de 47\% das famílias foram representadas por apenas uma espécie. Apenas 16 espécies foram comuns a todas as cinco parcelas. A diversidade da área foi alta $\left(\mathrm{H}^{\prime}=3,53\right)$ e a similaridade entre as parcelas segundo índice de Sørensen foi também alta. As espécies Sclerolobium paniculatum, Eremanthus glomerulatus, Schefflera macrocarpum, Ouratea hexasperma, Vochysia thyrsoidea, Guapira noxia, Caryocar brasiliense, Vellozia squamata, Qualea grandiflora e Emmotum nitens apresentaram os maiores valores de importância. As estimativas de densidade e de área basal por hectare foram de 1964 indivíduos e 13,28m², respectivamente. A diversidade foi equivalente a de outras áreas de cerrado sensu stricto na região, mas a densidade e a área basal foram mais elevadas.
\end{abstract}

Palavras-chave - diversidade, fitossociologia, cerrado, Brasil

ABSTRACT - (Phytosociology of an area of "cerrado denso" at the RECOR-IBGE, Brasília-DF, Brazil). This survey was conducted within a randomized block experiment set up in the RECOR - DF aiming to study the effect of fire in the cerrado. The sampling was conducted prior to the application of any treatments to assess the original status of the cerrado denso (dense savanna woodland) at the site. All woody individuals plus non-woody Velloziaceae over $5 \mathrm{~cm}$ diameter were included in the sample which consisted of five $1000 \mathrm{~m}^{2}(20 \mathrm{x} 50 \mathrm{~m})$ plots. Height and diameter at $30 \mathrm{~cm}$ from the ground level were measured. There were 982 individuals belonging to 63 species and 34 families. Around $47 \%$ of the families contained just one species. Only 16 species occurred in all plots. Alfa diversity was high $\left(\mathrm{H}^{\prime}=3.53\right)$ and Sørensen's Similarity Index was high between the plots. Sclerolobium paniculatum, Eremanthus glomerulatus, Schefflera macrocarpum, Ouratea hexasperma, Vochysia thyrsoidea, Guapira noxia, Caryocar brasiliense, Vellosia squamata, Qualea grandiflora and Emmotum nitens had the highest IVI. Density and basal area were 1964 and $13.28 \mathrm{~m}^{2} / \mathrm{ha}$, respectively. Diversity was similar to that found for several areas of cerrado sensu stricto in the region, but density and basal area were higher than at most sites.

Key words - diversity, phytosociology, cerrado, savanna woodland, Brazil

${ }^{1}$ Dep. de Ecologia, Universidade de Brasília CEP 70910-900, Brasília-DF

2 Dep. de Engenharia Florestal, Universidade de Brasília CP 04357- CEP 71910-970, Brasília-DF

${ }^{3}$ Projeto Fogo, bolsista do CNPq 


\section{Introdução}

O termo Cerrado designa uma vegetação de fisionomia e flora próprias, classificada dentro dos padrões de vegetação do mundo como savana (Eiten 1994). Muito rico floristicamente, sendo inclusive considerado como a flora mais rica entre as savanas mundiais (Klink 1996), o cerrado destaca-se com relação à biodiversidade devido a sua grande extensão, sua heterogeneidade vegetal e por conter trechos das três maiores bacias hidrográficas da América do Sul (Alho \& Martins 1995; Klink 1996). O Cerrado contribui ainda com cerca de $5 \%$ da diversidade da fauna e flora mundiais (Klink et al. 1995) e com cerca de $1 / 3$ da biota brasileira (Alho \& Martins 1995). A mais recente compilação de sua flora contabilizou 6429 espécies vasculares (Mendonça et al. 1998), número superior ao de grande parte de outras floras no mundo (Klink 1996). Dessas 6429 espécies, 6060 são angiospermas, o que representa $65 \%$ das 9300 estimadas por Gentry et al. (1997) para o Cerrado, Caatinga, Llanos, Chaco e Pantanal (Mendonça et al. 1998).

O Cerrado é notável também pela grande variação na fisionomia, apresentando formas florestais, savânicas e campestres (Ribeiro \& Walter 1998). Segundo Eiten (1994), a forma savânica mais comum no Brasil Central é o "arvoredo de escrube-e-árvores", chamada de cerrado sensu stricto (s.s.), fisionomia caraterizada por apresentar os estratos arbóreo e arbustivo bem definidos e cobertura arbórea variando de 10 a $60 \%$. Tal forma de cerrado pode variar quanto à densidade, podendo ser mais ralo ou mais denso. Uma forma florestal mais densa e mais alta, com árvores de $7 \mathrm{~m}$ ou mais de altura (chegando a atingir $15-18 \mathrm{~m}$ ) formando assim um dossel praticamente fechado é conhecida como cerradão. Dentre as formas florestais encontram-se ainda as matas de galeria, tipo de vegetação com predominância de espécies arbóreas e com formação de dossel, ocorrendo ao longo dos cursos fluviais de pequeno porte no Brasil Central. Já as formas campestres apresentam cobertura arbórea menor que o cerrado s.s. e arbustos mais esparsos sendo conhecidas como campo cerrado e campo sujo. A forma campestre mais extrema, na qual predomina uma vegetação herbácea principalmente graminosa, com raros arbustos e ausência completa de árvores é conhecida como campo limpo.

Apesar da sua importância, existe uma carência de informações, fisiológicas, ecológicas, florísticas e fitossociológicas, entre outras, acerca do bioma Cerrado e em muitos locais não foram ainda feitas coletas de material botânico (Felfili et al. 1993). Estes fatos, aliados à pequena área deste ecossistema teoricamente protegida em unidades de conservação legalizadas, as quais, em geral, são mal localizadas ou apresentam tamanho insuficiente para proteger sua biodiversidade (Dias 1994), dão uma idéia dos riscos da perda de informações sobre a florística da região. A carência de áreas de conservação no Cerrado pode ser ainda mais evidenciada quando se compara o esforço governamental em conservar os ecossistemas Amazônicos, os quais têm $12 \%$ da sua área protegida em Unidades de Conservação, contra menos de $2 \%$ no Cerrado (Klink 1996).

A forma de intervenção humana mais significativa no Cerrado tem sido a grande expansão das pastagens plantadas de lavouras comerciais (soja, milho, arroz, café, feijão e mandioca). Estimou-se que em 1995 um total de 38,6\% da área do Cerrado estariam sendo voltadas para agropecuária, lavouras, pastagens plantadas e terras produtivas não utilizadas (Klink 1996), havendo já estimativas da ordem de $60 \%$ (Mittermeyer et al. 1999). Essas alterações do uso da terra podem representar ameaças à biodiversidade (genética, de espécies e de ecossistemas) no Cerrado.

O objetivo deste trabalho foi a análise florística e fitossociológica de uma área de cerrado denso da Reserva Ecológica do IBGE - Ins- 
tituto Brasileiro de Geografia e Estatística (também conhecida como Reserva Ecológica do Roncador - RECOR), que posteriormente seria submetida a queimadas prescritas. Procurou-se caracterizar o status original da vegetação contribuindo para o conhecimento da vegetação nesta ocasião e para a formação de um banco de informações que permitirá avaliar a dinâmica da comunidade.

\section{Material e métodos}

A RECOR está localizada $35 \mathrm{~km}$ ao sul do centro de Brasília, com coordenadas de $15^{\circ} 55^{\prime}$ a $15^{\circ} 58^{\prime} \mathrm{S}, 4^{\circ} 52^{\prime}$ a $47^{\circ} 55^{\prime} \mathrm{W}$ e altitude variando de 1048 a 1160m. Ocupa uma área de 1360ha, a qual faz parte da Área de Proteção Ambiental Gama-Cabeça do Veado, juntamente com a Fazenda da Água Limpa e o Jardim Botânico, totalizando 10.000ha. Na reserva são realizados vários estudos, incluindo alguns de longa duração, como por exemplo, o PROJETO FOGO, liderado pelo Departamento de Ecologia da Universidade de Brasília. Daí, a importância do conhecimento florístico e fitossociológico desta área.

A fitofisionomia dominante na reserva é o cerrado lato sensu, o qual se apresenta sob formas de campo sujo, campo cerrado, cerrado s.s. e cerradão, apresentando também algumas matas, veredas, brejos e campos úmidos. Os solos predominantes são os latossolos vermelhos-amarelos, sendo que a área contém ainda significativas porções de latossolo vermelho-escuro e outros. Os valores médios de temperatura e precipitação na reserva são de $20,8^{\circ} \mathrm{C}$ e $1436 \mathrm{~mm}$, respectivamente (dados referentes ao período de 1980-92) (Pereira et al. 1993).

A área utilizada para o estudo está localizada na área experimental do Projeto Fogo, inicialmente selecionada devido a sua homogeneidade topográfica (baixa declividade) e edáfica (latossolo, predominante no bioma cerrado), por apresentar as formas fisionômicas mais comuns no cerrado e por estar protegida do fogo há 18 anos (Sato \& Miranda 1996). Neste projeto, foram estabelecidos blocos de 10ha $(200 \times 500 \mathrm{~m})$ seguindo a estratificação fisionômica do Cerrado na reserva, com o intuito de atender aos objetivos do projeto. No presente trabalho, foi utilizado o bloco denominado Quadrienal Modal, o qual foi subdividido em dez parcelas de $100 \times 100 \mathrm{~m}$. No centro de cinco parcelas alternadas foram demarcadas sub-parcelas de $20 \times 50 \mathrm{~m}$. Nesse trabalho, foram analisadas as sub-parcelas de número $361,363,365$, 372 e 374 dentro de um dos blocos de cerrado denso, totalizando 0,5ha (Fig. 1). A amostragem foi realizada no início do Projeto Fogo, e portanto, antes das queimadas prescritas propostas pelo mesmo. O tamanho de parcelas utilizado está padronizado com o projeto Biogeografia do Bioma Cerrado (Felfili et al. 1994; 1997) e o inventário contínuo do cerrado da Fazenda Água Limpa (Felfili \& Silva Jr. 1992). O embasamento para esse tamanho reside no fato de Cerrado sensu stricto ter uma cobertura lenhosa que varia de 10 a 60\% por definição (Eiten 1972), sendo portanto necessária a utilização de parcelas grandes para capturar uma fração significativa desta fisionomia por unidade amostral.

Todos os indivíduos com diâmetro maior que $5 \mathrm{~cm}$ a $30 \mathrm{~cm}$ da base do tronco foram identificados e tiveram seus diâmetro e altura medidos. A listagem das espécies vasculares da área encontra-se publicada em Pereira et al. (1993). Todas as espécies da área estão coletadas e o material depositado no Herbário do IBGE. Uma curva espécie/área foi montada para avaliar a suficiência da amostragem (Fig. 2).

Os parâmetros fitossociológicos de densidade (número de indivíduos ha ${ }^{-1}$ ), dominância (área basal $\mathrm{m}^{2}$ ha $^{-1}$ ), freqüência (porcentagem da ocorrência de uma espécie nas parcelas) foram calculados segundo Mueller-Dumbois \& Ellemberg (1974) e o índice de valor de importância -IVI(soma da densidade, dominância e frequência relativas), segundo Kent \& Coker (1992). Para a 

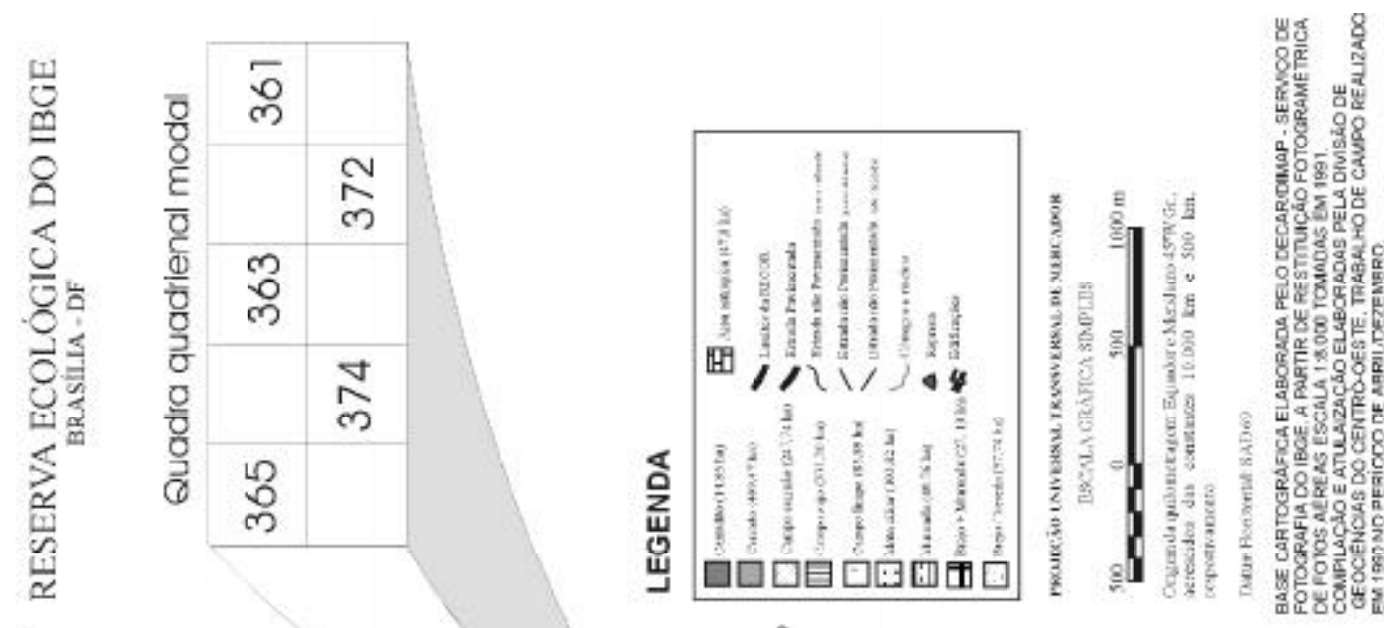

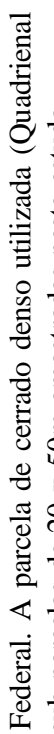

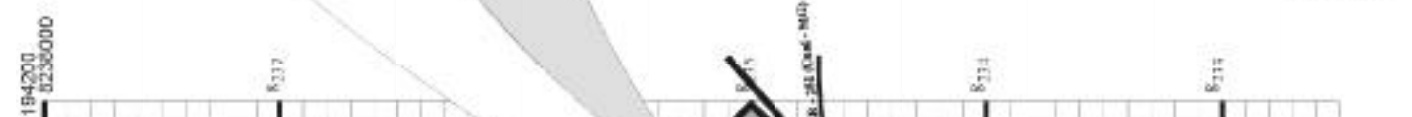

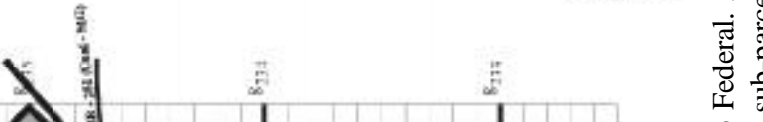

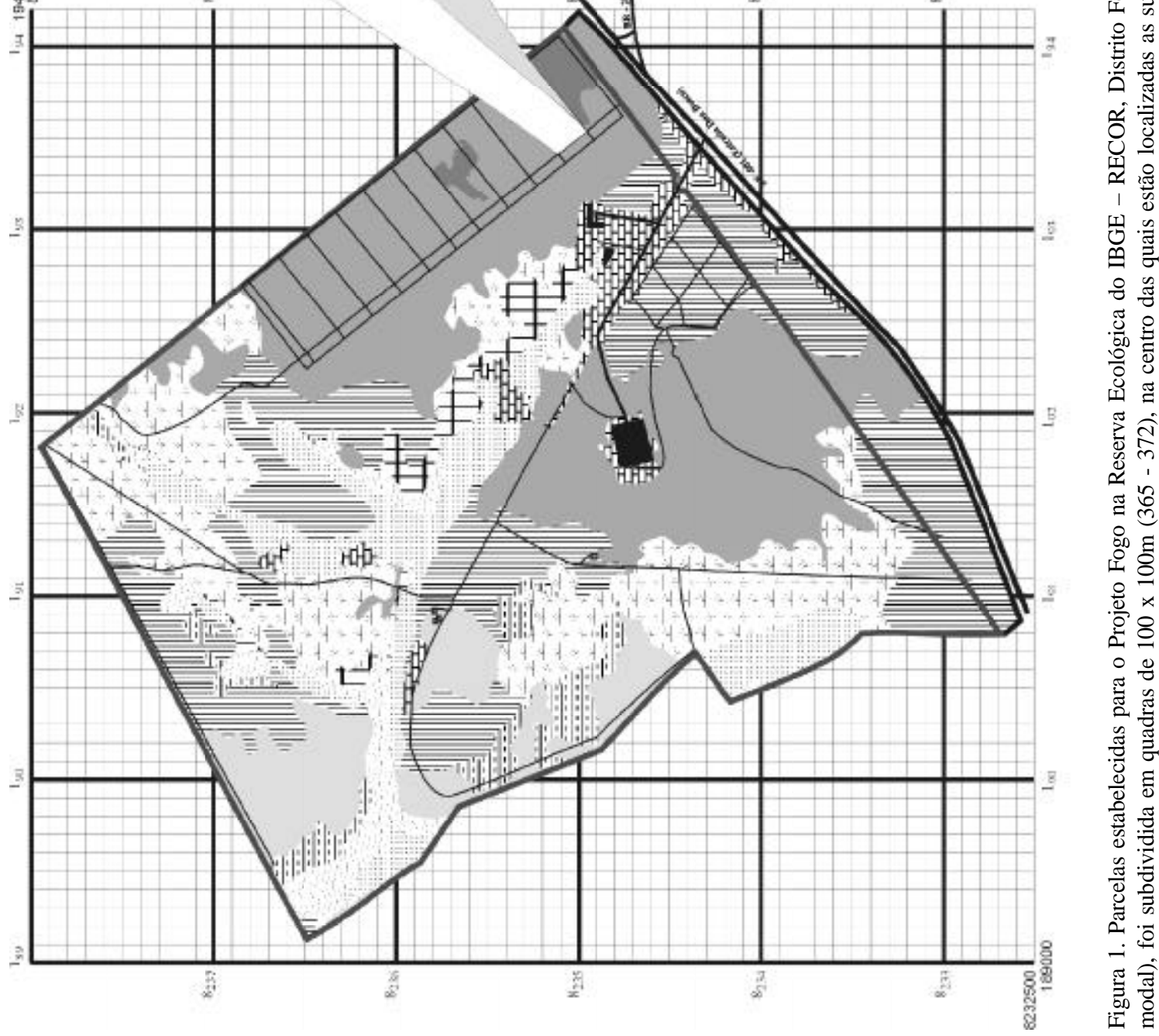




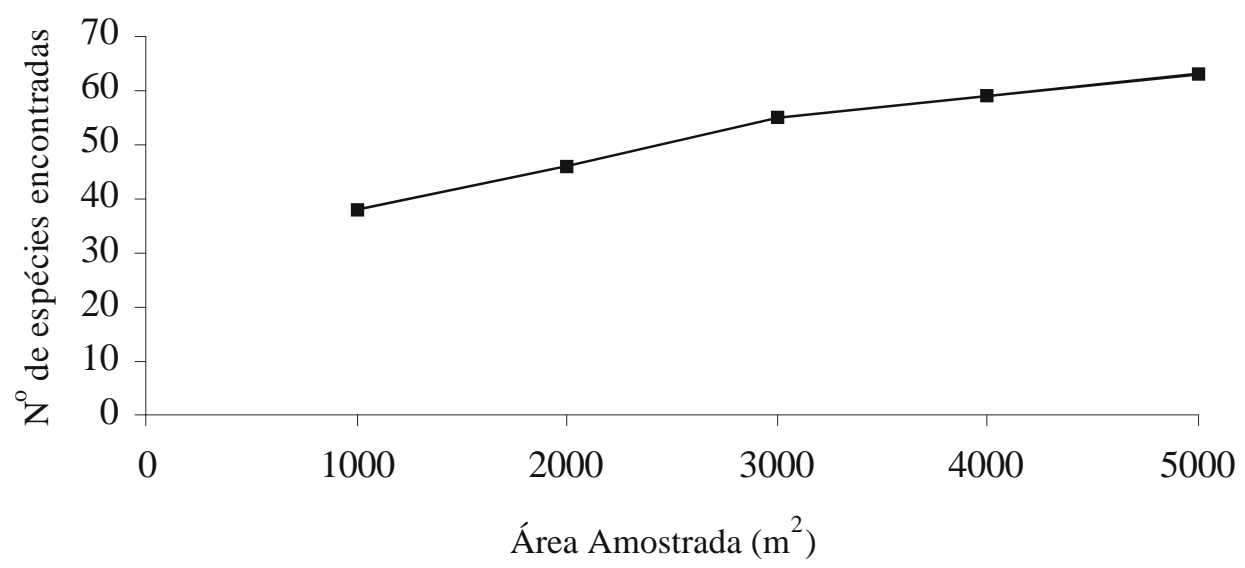

Figura 2: Curva espécie-área para a área de cerrado denso amostrada na Reserva Ecológica do IBGE - RECOR, Distrito Federal.

avaliação da diversidade florística da comunidade foi utilizado o índice de diversidade de Shannon na base $e$ a partir do programa MVSP (Kovach 1993). Esse índice varia de 0 a valores positivos, estando de modo geral entre 1,5 e 3,5, raramente ultrapassando 5,0 (Margurran 1988). A similaridade entre as parcelas foi avaliada pelos índices de Sørensen (qualitativo) e pelo de Czekanowski (quantitativo), calculados também pelo MVSP. Para o índice de Sørensen, quanto mais próximo de 1 , maior a similaridade, e uma similaridade maior que 0,5 já pode ser considerada alta.

A classificação da vegetação foi efetuada pelo método TWINSPAN - "Two-Way Indicator Species Analisys" (Hill 1979), o qual constrói uma tabela dicotômica pela identificação de espécies preferenciais. Resume os dados através de uma classificação integrada de ambas as amostras e espécies e sua divisão é clara pois coloca as amostras mais similares juntas (Gauch 1982). A partir desse método, procura-se identificar padrões na distribuição das espécies que possam ser associados com o ambiente e corroborados com observações de campo (Kent \& Coker 1992).

\section{Resultados e discussão}

Curva espécie-área - pela curva espécie-área apresentada na Figura 2, pode-se observar que a partir de $3000 \mathrm{~m}^{2}$ de área amostrada começou a haver uma redução no número de espécies novas encontradas, sendo que com $4000 \mathrm{~m}^{2}$, ou seja com $80 \%$ da área inicialmente proposta, $92 \%$ do total de espécies já haviam sido amostradas. No entanto, a curva ainda não atingiu a assíntota. Riqueza Florística e a Diversidade - na área amostrada de Cerrado denso, foram encontradas 63 espécies distribuídas em 47 gêneros e em 34 famílias (Tab. 1), sendo que 50\% das famílias e 74,47\% dos gêneros foram representados por apenas uma espécie (Fig. 3 e 4). A diversidade da área, segundo o índice de Shannon foi 3,53 com equabilidade de 0,85 o qual equivale com os encontrados para outras áreas de cerrado do Distrito Federal e de Goiás (Tab. 2). Esses índices para as áreas de Cerrado são altos quando comparados com aqueles obtidos para lugares em outras formações brasileiras como por exemplo as Florestas chuvosas Atlânticas e Amazônicas as quais possuem índices que vão de 3,72 a 4,30 (Silva \& Leitão Filho 1982), assim como para as matas de galeria inseridas no Cerrado (Tab. 2). O número de espécies encontrado neste trabalho também está dentro da amplitude comumente observada nos cerrados do DF, os quais ficam entre 50 e 80 (Tab. 2).

Fitossociologia - as famílias que tiveram os maiores valores de IVI foram Vochysiaceae 


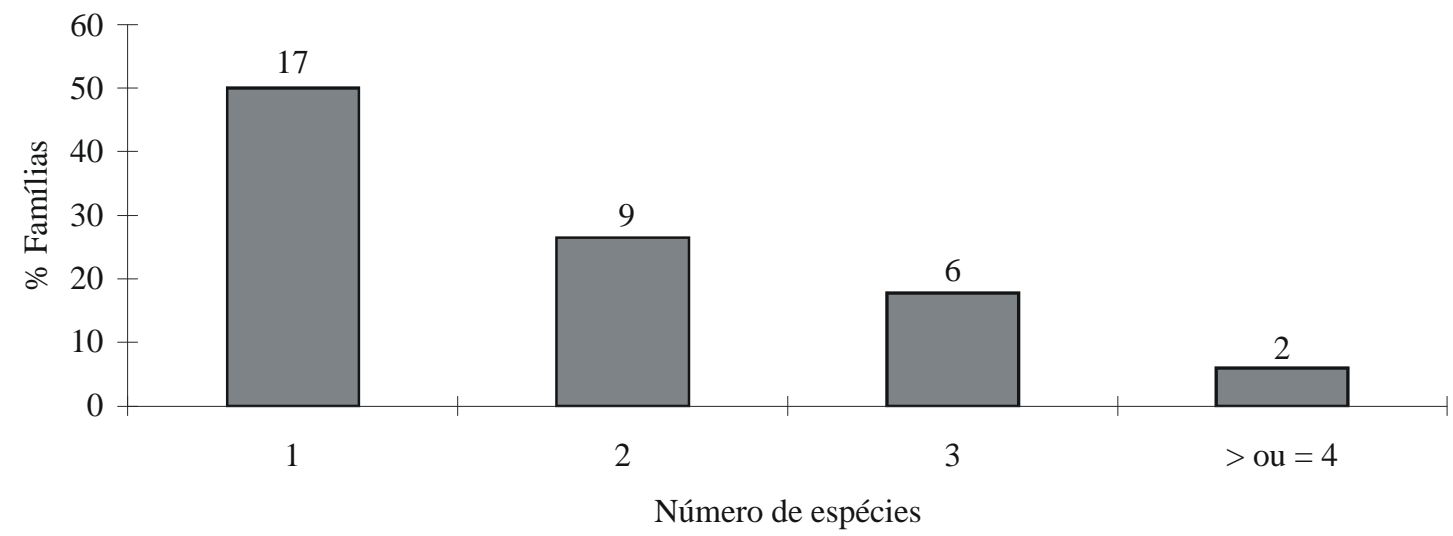

Figura 3. Distribuição, em porcentagem, das famílias pelo número de espécies de uma área de cerrado denso da Reserva Ecológica do IBGE - RECOR, Distrito Federal. Os números sobre as barras representam os valores absolutos de famílias.

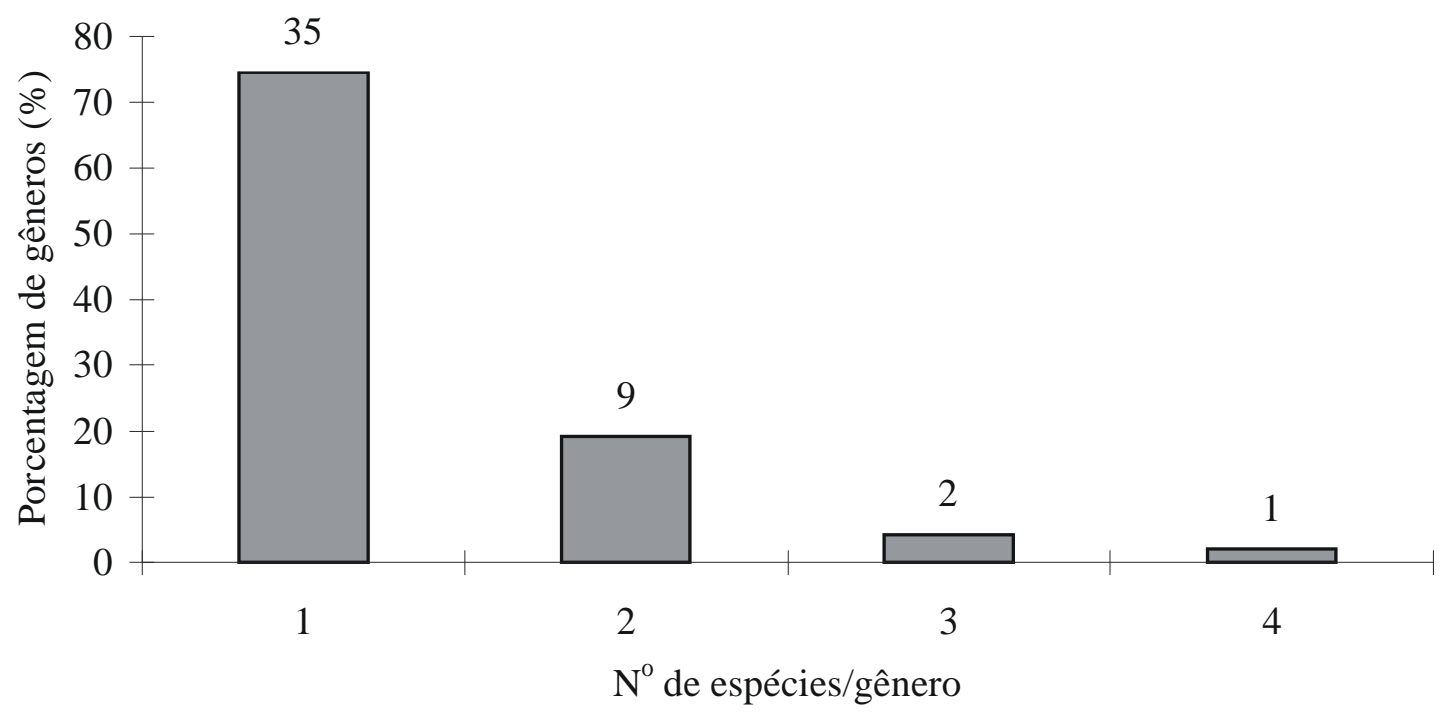

Figura 4. Distribuição, em porcentagem, dos gêneros pelo número de espécies de uma área de cerrado denso da Reserva Ecológica do IBGE - RECOR, Distrito Federal. Os números sobre as barras representam os valores absolutos dos gêneros. 
Fitossociologia de uma área de cerrado denso na RECOR-IBGE, Brasília-DF.

Tabela 1: Fitossociologia de uma área de cerrado denso da Reserva Ecológica do IBGE - RECOR, Distrito Federal.

\begin{tabular}{|c|c|c|c|c|c|c|c|c|}
\hline \multirow[t]{2}{*}{ Espécie } & \multirow[t]{2}{*}{ Família } & \multicolumn{2}{|c|}{$\begin{array}{c}\text { Densidade } \\
(\mathrm{n} / \mathrm{ha})\end{array}$} & \multicolumn{2}{|c|}{ Freqüência } & \multicolumn{2}{|c|}{$\begin{array}{c}\text { Dominância } \\
\left(\mathrm{m}^{2} / \mathrm{ha}\right)\end{array}$} & \multirow[t]{2}{*}{ IVI } \\
\hline & & Abs. & Rel. & Abs. & Rel. & Abs. & Rel. & \\
\hline Sclerolobium paniculatum & LEGUMINOSAE - CAESALPINOIDEAE & 84 & 4,28 & 100 & 2,53 & 1,28 & 9,61 & 16,41 \\
\hline Eremanthus glomerulatus & COMPOSITAE & 176 & 8,96 & 100 & 2,53 & 0,63 & 4,76 & 16,25 \\
\hline Morta & & 106 & 5,40 & 100 & 2,53 & 0,90 & 6,80 & 14,72 \\
\hline Schefflera macrocarpum & ARALIACEAE & 152 & 7,74 & 100 & 2,53 & 0,58 & 4,37 & 14,63 \\
\hline Ouratea hexasperma & OCHNACEAE & 136 & 6,92 & 100 & 2,53 & 0,53 & 3,98 & 13,43 \\
\hline Vochysia thyrsoidea & VOCHYSIACEAE & 62 & 3,16 & 100 & 2,53 & 1,00 & 7,54 & 13,22 \\
\hline Guapira noxia & NYCTAGINACEAE & 98 & 4,99 & 100 & 2,53 & 0,69 & 5,17 & 12,68 \\
\hline Caryocar brasiliensis & CARYOCARACEAE & 68 & 3,46 & 80 & 2,02 & 0,74 & 5,61 & 11,09 \\
\hline Vellozia squamata & VELLOZIACEAE & 112 & 5,70 & 100 & 2,53 & 0,34 & 2,57 & 10,80 \\
\hline Qualea grandiflora & VOCHYSIACEAE & 58 & 2,95 & 80 & 2,02 & 0,71 & 5,33 & 10,31 \\
\hline Emmotum nitens & ICACINACEAE & 52 & 2,65 & 40 & 1,01 & 0,88 & 6,59 & 10,25 \\
\hline Dalbergia miscolobium & LEGUMINOSAE - PAPILIONOIDEAE & 46 & 2,34 & 100 & 2,53 & 0,44 & 3,30 & 8,16 \\
\hline Roupala montana & PROTEACEAE & 64 & 3,26 & 100 & 2,53 & 0,27 & 2,03 & 7,81 \\
\hline Byrsonima crassifolia & MALPHIGHIACEAE & 54 & 2,75 & 100 & 2,53 & 0,26 & 1,96 & 7,24 \\
\hline Styrax ferrugineus & STYRACACEAE & 50 & 2,55 & 100 & 2,53 & 0,22 & 1,64 & 6,71 \\
\hline Blepharocalyx salicifolius & MYRTACEAE & 30 & 1,53 & 80 & 2,02 & 0,40 & 3,00 & 6,55 \\
\hline Aspidosperma tomentosum & APOCYNACEAE & 52 & 2,65 & 80 & 2,02 & 0,25 & 1,86 & 6,53 \\
\hline Qualea parviflora & VOCHYSIACEAE & 42 & 2,14 & 60 & 1,52 & 0,36 & 2,70 & 6,36 \\
\hline Miconia ferruginata & MELASTOMATACEAE & 40 & 2,04 & 100 & 2,53 & 0,21 & 1,61 & 6,17 \\
\hline Symplocos rhamnifolia & SYMPLOCACEAE & 28 & 1,43 & 100 & 2,53 & 0,24 & 1,82 & 5,77 \\
\hline Rapanea guianensis & MYRSINACEAE & 46 & 2,34 & 80 & 2,02 & 0,15 & 1,10 & 5,46 \\
\hline Rourea induta & CONNARACEAE & 30 & 1,53 & 100 & 2,53 & 0,12 & 0,88 & 4,94 \\
\hline Palicourea rigida & RUBIACEAE & 38 & 1,93 & 80 & 2,02 & 0,10 & 0,77 & 4,72 \\
\hline Aspidosperma macrocarpon & APOCYNACEAE & 30 & 1,53 & 80 & 2,02 & 0,14 & 1,02 & 4,57 \\
\hline Erythroxylum suberosum & ERYTHROXYLACEAE & 20 & 1,02 & 100 & 2,53 & 0,05 & 0,36 & 3,91 \\
\hline Qualea multiflora & VOCHYSIACEAE & 20 & 1,02 & 60 & 1,52 & 0,15 & 1,11 & 3,64 \\
\hline Stryphnodendron adstringens & LEGUMINOSAE - MIMOSOIDEAE & 16 & 0,81 & 80 & 2,02 & 0,09 & 0,71 & 3,55 \\
\hline Guapira graciflora & NYCTAGINACEAE & 20 & 1,02 & 80 & 2,02 & 0,05 & 0,35 & 3,39 \\
\hline Kielmeyera coriacea & GUTTIFERAE & 12 & 0,61 & 100 & 2,53 & 0,03 & 0,21 & 3,35 \\
\hline Syagrus flexuosa & PALMAE (ARECACEAE) & 16 & 0,81 & 80 & 2,02 & 0,06 & 0,45 & 3,28 \\
\hline Lafoensia pacari & LYTHRACEAE & 10 & 0,51 & 80 & 2,02 & 0,07 & 0,51 & 3,04 \\
\hline Dimorphandra mollis & LEGUMINOSAE - MIMOSOIDEAE & 8 & 0,41 & 80 & 2,02 & 0,07 & 0,52 & 2,95 \\
\hline Strychnos pseudoquina & LOGANIACEAE & 14 & 0,71 & 60 & 1,52 & 0,08 & 0,58 & 2,81 \\
\hline Vochysia elliptica & VOCHYSIACEAE & 10 & 0,51 & 80 & 2,02 & 0,03 & 0,26 & 2,79 \\
\hline Eriotheca pubescens & BOMBACACEAE & 10 & 0,51 & 40 & 1,01 & 0,12 & 0,92 & 2,44 \\
\hline Davilla elliptica & DILLENIACEAE & 10 & 0,51 & 60 & 1,52 & 0,04 & 0,30 & 2,33 \\
\hline Hymenaea stigonocarpa & LEGUMINOSAE - CAESALPINOIDEAE & 10 & 0,51 & 40 & 1,01 & 0,10 & 0,74 & 2,26 \\
\hline Diospyros burchellii & EBENACEAE & 10 & 0,51 & 40 & 1,01 & 0,08 & 0,59 & 2,11 \\
\hline Tabebuia ochracea & BIGNONIACEAE & 8 & 0,41 & 60 & 1,52 & 0,02 & 0,16 & 2,09 \\
\hline Salacia crassifolia & HIPPOCRATEACEAE & 8 & 0,41 & 60 & 1,52 & 0,02 & 0,15 & 2,08 \\
\hline Enterolobium ellipticum & LEGUMINOSAE - MIMOSOIDEAE & 6 & 0,31 & 40 & 1,01 & 0,06 & 0,43 & 1,74 \\
\hline Connarus suberosus & CONNARACEAE & 8 & 0,41 & 40 & 1,01 & 0,04 & 0,30 & 1,72 \\
\hline Piptocarpha rotundifolia & COMPOSITAE & 8 & 0,41 & 40 & 1,01 & 0,03 & 0,19 & 1,61 \\
\hline Byrsonima coccolobifolia & MALPHIGHIACEAE & 6 & 0,31 & 40 & 1,01 & 0,04 & 0,29 & 1,60 \\
\hline Qualea dichotoma & VOCHYSIACEAE & 2 & 0,10 & 20 & 0,51 & 0,13 & 0,95 & 1,56 \\
\hline Couepia grandiflora & CHRYSOBALANACEAE & 6 & 0,31 & 40 & 1,01 & 0,03 & 0,23 & 1,55 \\
\hline Bowdichia virgiloides & LEGUMINOSAE - PAPILIONOIDEAE & 6 & 0,31 & 20 & 0,51 & 0,09 & 0,70 & 1,51 \\
\hline Pouteria ramiflora & SAPOTACEAE & 6 & 0,31 & 20 & 0,51 & 0,09 & 0,66 & 1,47 \\
\hline Psidium warmingianum & MYRTACEAE & 6 & 0,31 & 40 & 1,01 & 0,02 & 0,13 & 1,44 \\
\hline Symplocos sp. & SYMPLOCACEAE & 6 & 0,31 & 40 & 1,01 & 0,02 & 0,12 & 1,43 \\
\hline
\end{tabular}


Tabela 1. (continuação).

\begin{tabular}{|c|c|c|c|c|c|c|c|c|}
\hline \multirow[t]{2}{*}{ Espécie } & \multirow[t]{2}{*}{ Família } & \multicolumn{2}{|c|}{$\begin{array}{l}\text { Densidade } \\
\text { (n/ha) }\end{array}$} & \multicolumn{2}{|c|}{ Freqüência } & \multicolumn{2}{|c|}{$\begin{array}{c}\text { Dominância } \\
\left(\mathrm{m}^{2} / \mathrm{ha}\right)\end{array}$} & \multirow[t]{2}{*}{ IVI } \\
\hline & & Abs. & Rel. & Abs. & Rel. & Abs. & Rel. & \\
\hline Acosmium dasycarpum & LEGUMINOSAE - CAESALPINOIDEAE & 4 & 0,20 & 40 & 1,01 & 0,01 & 0,10 & 1,31 \\
\hline Byrsonima verbascifolia & MALPHIGHIACEAE & 4 & 0,20 & 40 & 1,01 & 0,01 & 0,09 & 1,30 \\
\hline Erythoxylum tortuosum & ERYTHROXYLACEAE & 4 & 0,20 & 40 & 1,01 & 0,01 & 0,08 & 1,29 \\
\hline Pterodon pubescens & LEGUMINOSAE - PAPILIONOIDEAE & 6 & 0,31 & 20 & 0,51 & 0,05 & 0,38 & 1,19 \\
\hline Banisteriopsis $s p$ & MALPHIGHIACEAE & 8 & 0,41 & 20 & 0,51 & 0,03 & 0,22 & 1,13 \\
\hline Caryocar coriaceae & CARYOCARACEAE & 2 & 0,10 & 20 & 0,51 & 0,04 & 0,28 & 0,88 \\
\hline Austroplenckia populnea & CELASTRACEAE & 2 & 0,10 & 20 & 0,51 & 0,03 & 0,23 & 0,83 \\
\hline Pouteria torta & SAPOTACEAE & 2 & 0,10 & 20 & 0,51 & 0,03 & 0,20 & 0,81 \\
\hline Tocoyena formosa & RUBIACEAE & 4 & 0,20 & 20 & 0,51 & 0,01 & 0,10 & 0,80 \\
\hline Miconia pohliana & MELASTOMATACEAE & 2 & 0,10 & 20 & 0,51 & 0,01 & 0,11 & 0,71 \\
\hline Tabebuia chrysotricha & BIGNONIACEAE & 2 & 0,10 & 20 & 0,51 & 0,01 & 0,07 & 0,68 \\
\hline Diospyros hispida & EBENACEAE & 2 & 0,10 & 20 & 0,51 & 0,01 & 0,06 & 0,66 \\
\hline Erythoxylum deciduum & ERYTHROXYLACEAE & 2 & 0,10 & 20 & 0,51 & 0,01 & 0,05 & 0,66 \\
\hline Eremanthus goyazensis & COMPOSITAE & 2 & 0,10 & 20 & 0,51 & 0,00 & 0,03 & 0,64 \\
\hline Hancornia speciosa & APOCYNACEAE & 2 & 0,10 & 20 & 0,51 & 0,00 & 0,03 & 0,64 \\
\hline Total & & 1964 & 100,00 & 3960 & 100,00 & 13,277 & 100,00 & 300,00 \\
\hline
\end{tabular}

(com seis espécies), Leguminosae Caesalpinoideae (com três espécies), Compositae e Nyctaginaceae (com duas espécies), Araliaceae e Ochnaceae (com apenas uma espécie) (Fig. 5). As famílias que se destacaram em densidade foram Vochysiaceae (194 indivíduos/ha), Compositae (186 indivíduos/ha), Araliaceae (152 indivíduos/ha), Ochnaceae (136 indivíduos/ha), Nyctaginaceae (118 indivíduos/ ha) e Velloziaceae (112 indivíduos/ha), totalizando $45,72 \%$ da densidade total de indivíduos. Já as famílias que se destacaram em dominância foram Vochysiaceae $\left(708,84 \mathrm{~m}^{2} / \mathrm{ha}\right)$, Leguminosae - Caesalpinoideae $\left(413,42 \mathrm{~m}^{2} / \mathrm{ha}\right)$, Icacinaceae $\left(260,96 \mathrm{~m}^{2} / \mathrm{ha}\right)$, Caryocariaceae (232,84 $\left.\mathrm{m}^{2} / \mathrm{ha}\right)$, Nyctaginaceae $\left(218,6 \mathrm{~m}^{2} / \mathrm{ha}\right) \mathrm{e}$ Compositae $\left(197,6 \mathrm{~m}^{2} / \mathrm{ha}\right)$ totalizando $51,32 \%$ da dominância total.

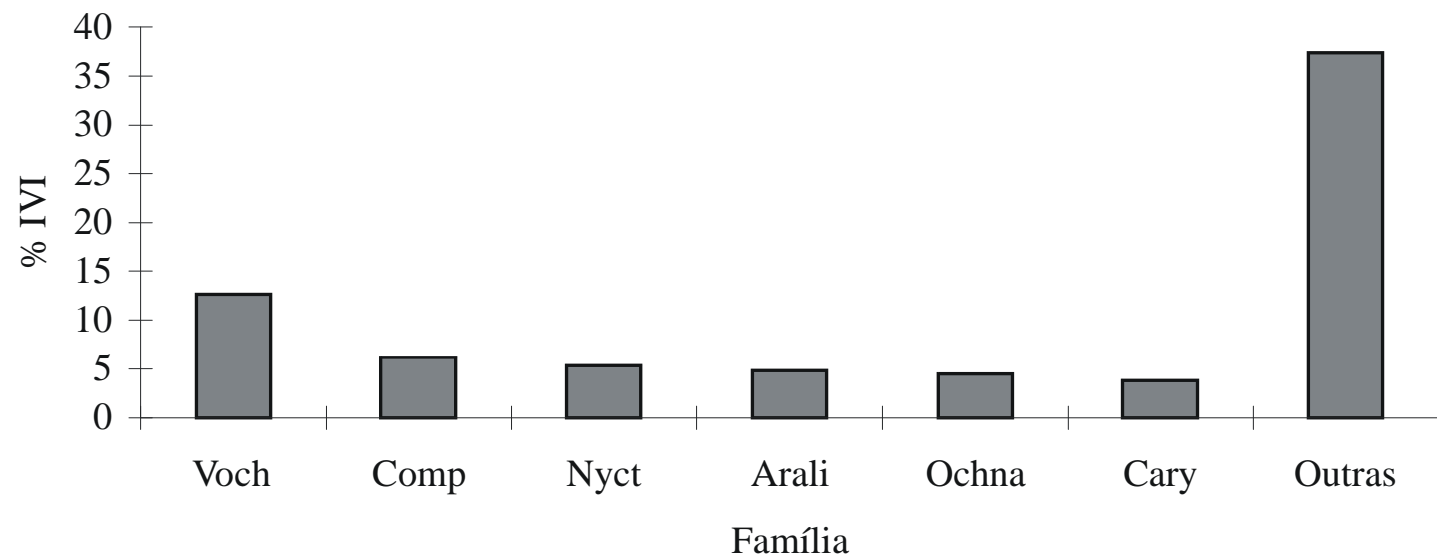

Figura 5. Distribuição em porcentagem, dos valores de IVI por família de uma área de cerrado denso da Reserva Ecológica do IBGE - RECOR, Distrito Federal. Os números sobre as barras representam os valores absolutos de IVI. Voch = Vochysiaceae; Leg Caes = Leguminosae - Caesalpinoideae; Comp = Compositae; Nyct = Nyctaginaceae; Arali $=$ Araliaceae Ochna $=$ Ochnaceae , Cary $=$ Caryocaraceae . 
Tabela 2: Comparação dos principais parâmetros fitossociológicos entre diversas áreas no Distrito Federal. IBGE (RECOR - Cerrado Denso), ESEC-AE (Águas Emendadas - cerrado sensu stricto), APA s.s. (Gama - Cabeça do Veado - cerrado s.s.), APA (Gama - Cabeça do Veado - cerradão), PNB (Parque Nacional de Brasília - cerrado s.s.), PEN (Parque Ecológico Norte - cerrado s.s.), FAL s.s. (Fazenda Água Limpa - cerrado s.s.), FAL (Fazenda Água Limpa - Cerradão), CPAC (Centro de Pesquisa Agropecuária do Cerrado - cerradão), GAMA (Mata de Galeria do Córrego Gama) e AÇUD (Mata de Galeria do Córrego Açudinho).

\begin{tabular}{ccccccll}
\hline Local & $\begin{array}{c}\text { Riqueza } \\
\text { Famílias }\end{array}$ & $\begin{array}{c}\text { Nonsidade } \\
\left(\mathrm{ha}^{-1}\right)\end{array}$ & $\begin{array}{c}\text { Área Basal } \\
\left(\mathrm{m}^{2} . \mathrm{ha}^{-1}\right)\end{array}$ & $\begin{array}{c}\% \text { Árvores } \\
\text { Mortas }\end{array}$ & $\begin{array}{c}\text { Índice de } \\
\text { Shannon }\end{array}$ & Referência \\
\hline IBGE & 63 & 34 & 1964 & 13,28 & 5,4 & 3,53 & Presente trabalho \\
ESEC-AE & 72 & 31 & 1396 & 10,76 & 5,11 & 3,62 & Felfili \& Silva Jr 1993 \\
APA s.s. & 67 & 32 & 1394 & 10,64 & 5,67 & 3,56 & Felfili \& Silva Jr 1993 \\
APA & 51 & 26 & 960 & 24,00 & 8,59 & 3,17 & Felfili et al. 1994 \\
PNB & 55 & 26 & 1036 & 8,32 & 13,71 & 3,34 & Felfili et al. 1993, 1997 \\
PEN & 52 & 29 & 552 & 7,99 & 10 & 3,24 & Rossi et al. 1998 \\
FAL s.s. & 61 & 30 & 958 & 7,34 & - & 3,46 & Felfili \& Silva Jr 1992 \\
FAL & 60 & 29 & 815 & 21,94 & - & 3,42 & Felfili \& Silva Jr. 1992 \\
CPAC & 81 & 35 & 2231 & 20,92 & - & - & Ribeiro et al. 1985 \\
GAMA ${ }^{2}$ & 93 & 44 & 649 & 30,40 & 3,4 & 3,84 & Felfili 1995 \\
AÇUD & 135 & 52 & 1706 & 33,64 & 7,6 & 4,25 & Sampaio et al. 1997 \\
\hline
\end{tabular}

1 Todos os trabalhos adotaram base e para o cálculo do índice e diâmetro mínimo de 5cm, exceto em 2 .

2 Foram avaliados apenas os indivíduos com diâmetro acima de $10 \mathrm{~cm}$.

As famílias Vochysiaceae e Leguminosae também se destacaram em importância em estudos de diversas áreas de cerrado (Felfili et al. 1993). Vochysiaceae é uma família típica e importante inclusive nas Matas de Galeria (Felfili 1994). Muitas espécies de Vochysiaceae são típicas alumínio-acumuladoras (Haridasan \& Araújo 1988) e isso lhes proporciona uma vantagem competitiva para crescer com sucesso nos solos ácidos dos Cerrados, ricos em alumínio (Felfili \& Silva Jr. 1993).

Os gêneros mais ricos em número de espécies foram Qualea (4), Byrsonima e Erythroxylum (3). As dez espécies mais importantes foram Sclerolobium paniculatum, Eremanthus glomerulatus, Schefflera macrocarpum, Ouratea hexasperma, Vochysia thyrsoidea, Guapira noxia, Caryocar brasiliense, Vellozia squamata, Qualea grandiflora e Emmotum nitens (Tab. 1). Elas totalizaram $43,2 \%$ do IVI total, $55,8 \%$ da dominância total e 50,9\% da densidade total.

Dessa forma, essas espécies podem ser consideradas as que tiveram maior sucesso na ex- ploração dos recursos do ambiente. Os indivíduos mortos em pé apresentaram o $3^{\circ}$ maior IVI, perfazendo $6,8 \%$ da dominância total e $5,4 \%$ da densidade total, valor semelhante ao encontrado para a APA Gama-Cabeça do Veado $(5,67 \%)$ e para outras áreas de cerrado próximas ao Distrito Federal (Felfili et al. 1993; 1994).

As espécies que se destacaram na densidade foram Eremanthus glomerulatus, Schefflera macrocarpum, Ouratea hexasperma, e Vellozia squamata, representando $29,32 \%$ da densidade total de indivíduos. Todas estas espécies (com ressalva a Schefflera macrocarpum) se caracterizam por serem de pequeno porte (Mendonça et al. 1998), o que explica o destaque para a densidade e não para a dominância. Assim, apresentam muitos indivíduos, os quais são relativamente pequenos, com alturas atingindo no máximo 4,6m (sendo que o valor máximo se aplica ao caso de Schefflera macrocarpum). Já em relação à dominância Sclerolobium paniculatum, Vochysia thyrsoidea, Emmotum nitens, Caryocar brasiliense e Qualea grandiflora foram as es- 
pécies que tiveram mais destaque, totalizando 34,68\% da dominância total. Estas espécies são caracterizadas como árvores (Mendonça et al. 1998), e apresentam alturas atingindo até 6,3m. De maneira geral, as espécies com IVI altos apresentaram distribuição ampla, uma vez que tiveram densidades e freqüências altas. Uma ressalva deve ser feita a Emmotum nitens, a qual foi encontrada em densidades altas, entretanto, em freqüências baixas. Isto sugere que a espécie tem uma distribuição mais agregada, o que pode estar relacionado a fatores ambientais específicos condicionando a distribuição local das espécies (Rossi et al. 1998).

Dezesseis espécies de diferentes famílias foram comuns a todas as cinco parcelas: Sclerolobium paniculatum, Eremanthus glomerulatus, Schefflera macrocarpum, Ouratea hexasperma, Vochysia thyrsoidea, Guapira noxia, Vellozia squamata, Dalbergia miscolobium, Roupala montana, Byrsonima crassiflora, Styrax ferrugineus, Miconia ferruginata, Symplocos rahmnifolia, Rourea induta, Erythroxylum suberosum e Kielmeyera coriacea, sendo que as últimas quatro espécies apresentaram poucos indivíduos, apesar da alta freqüência.

Quatorze espécies apareceram em apenas uma das parcelas: Qualea dichotoma, Bowdichia virgiloides, Pouteria ramiflora, Pterodon pubescens, Banisteriopsis sp., Austroplenckia populnea, Pouteria torta, Tocoyena formosa, Miconia pohliana, Tabebuia chrysotricha, Diospyros hispida, Erythroxylum deciduum, Eremanthus goyazensis, e Hancornia speciosa. As espécies que foram representadas por apenas um indivíduo foram: Austroplenckia populnea $(0,83)$, Pouteria torta $(0,81)$, Miconia pohliana $(0,71)$, Tabebuia chrysotricha $(0,68)$, Diospyros hispida $(0,66)$, Erythroxylum deciduum $(0,66)$, Eremanthus goyazensis $(0,64)$, Hancornia speciosa $(0,64)$. Vinte e três espécies apresentaram IVI menores que $10 \%$ do maior valor de IVI encontrado $(16,41)$, portanto esta comunidade se caracteriza pela existência de poucas espécies dominantes.

Foram amostrados ao todo 982 indivíduos, sendo que as estimativas de densidade e de área basal por hectare foram de 1964 indivíduos e $13,28 \mathrm{~m}^{2}$, respectivamente. O intervalo de confiança para densidade média por hectare foi $\mathrm{P}[1964 \pm 532]=0,95$ e para área basal média foi $P[13,28 \pm 4,28]=0,95$. Cerca de $64 \%$ das espécies apresentaram 2 a 27 indivíduos/ ha (Fig. 6).

Em um levantamento fitossociológico realizado para uma área de cerrado $s$. $s$. na APA Gama Cabeça do Veado por Felfili et al. (1993; 1994), as nove espécies mais importantes foram: Ouratea hexasperma, Qualea parviflora, Qualea grandiflora, Caryocar brasiliense, Dalbergia miscolobium, Styrax ferrugineus, Schefflera macrocarpum, Sclerolobium paniculatum e Byrsonima crassa. Dessas nove espécies, apenas quatro concordam com a relação das dez espécies mais importantes encontrada neste presente trabalho, apesar de todas aquelas restantes terem sido também encontradas no levantamento do IBGE. No mesmo levantamento feito na APA Gama Cabeça do Veado, considerou-se também uma área de cerradão, na qual as seguintes espécies foram as mais importantes: Emmotum nitens, Blepharocalyx salicifolius, Qualea grandiflora, Sclerolobium paniculatum, Caryocar brasiliense, Pterodon pubescens, Aspidosperma tomentosum, Myrsine coriacea e Nectandra sp. Da mesma forma, dessas nove espécies, quatro concordam com as encontradas para a área de cerrado denso do IBGE, entretanto, das cinco restantes, duas não foram amostradas no levantamento do IBGE. Já no estudo feito em uma área de cerradão em Planaltina-DF por Ribeiro et al. (1985) as seguintes espécies foram relacionadas como as mais importantes: Emmotum nitens, Ocotea spixiana, Tapirira guianensis, Siparuna guianensis, Maprounea guianensis, Diospyrus 


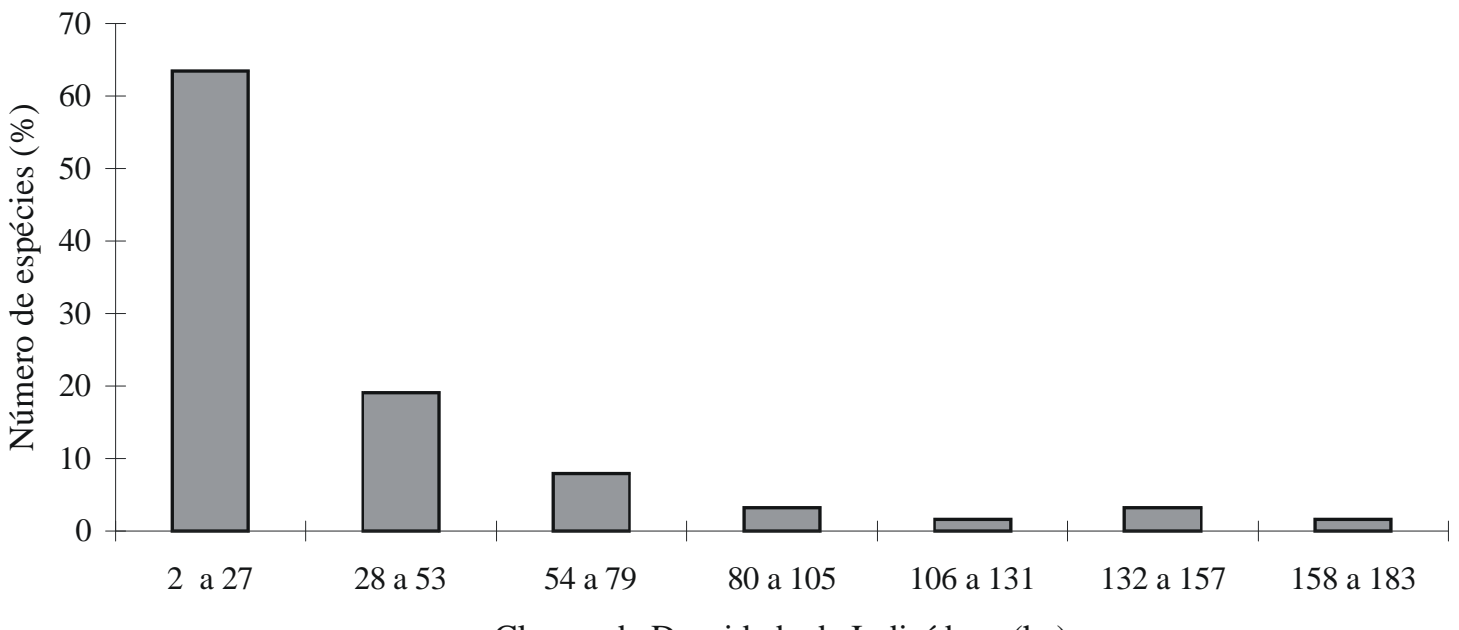

Classes de Densidade de Indivíduos (ha)

Figura 6. Relação entre porcentagem de espécies e densidade de indivíduos/ha em uma área de cerrado denso da Reserva Ecológica do IBGE - RECOR, Distrito Federal.

sericea, Qualea grandiflora, Xylopia aromatica, Bowdichia virgiloides e Miconia sellowiana. Mesmo estando duas dessas espécies entre as mais importantes para a área de cerrado denso do IBGE, sendo inclusive uma delas (Emmotum nitens) considerada como preferencial de cerradão (Felfili \& Silva Jr. 1992), nenhuma das outras foi encontrada na área amostrada, mostrando a maior afinidade florística desta com as áreas de cerrado s.s e de cerradão estudado por Felfili et al. (1993; 1994) na APA Gama Cabeça do Veado, da qual a reserva do IBGE faz parte.

Considerando o número total de espécies encontradas nos estudos de Felfili et al. (1993; 1994), observa-se que 79\% (53 em 67) das espécies listadas para o cerrado s.s. e 66\% (34 em 51) das espécies listadas para o cerradão também foram encontradas no presente trabalho, enquanto que das 81 espécies listadas para o cerradão estudado por Ribeiro et al. (1985), apenas $22(27 \%)$ também ocorreram no cerrado denso do IBGE. Dessa forma, pode-se sugerir que haja uma maior semelhança entre o cerrado denso do IBGE com uma área de cerrado típico do que com as áreas de cerradão citadas, sendo que dentre estas, a área de cerradão de
Planaltina se diferencia mais, talvez devido à maior distância entre elas (Tab. 3). Entretanto, segundo o levantamento fitossociológico de diversas áreas de cerrado s.s e de cerradão no DF e em Goiás feito por Felfili et al. (1994), as amplitudes de densidade (indivíduos/ha) e área basal $\left(\mathrm{m}^{2} / \mathrm{ha}\right)$ encontradas para o cerrado s.s. foram 664-1396 e 5,79-11,30, respectivamente, sendo portanto menores que os valores encontrados para o cerrado denso do IBGE. Embora floristicamente haja uma maior afinidade entre áreas de cerrado s.s. e a área de cerrado denso em questão, estruturalmente este último é mais denso e apresenta área basal acima do encontrado usualmente. Por outro lado, os valores de densidade e área basal encontrados para o cerradão são bem maiores que os encontrados no presente estudo (960-2082 indivíduos/ ha e 17,47-24 $\mathrm{m}^{2} / \mathrm{ha}$ ). Assim, considerando-se que o cerrado típico pode apresentar uma ampla variação na densidade de indivíduos, uma vez que pode apresentar cobertura arbórea entre 10 e $60 \%$, sugere-se que a classificação da área como cerrado denso é apropriada.

A distribuição de diâmetro de todos os indivíduos vivos e mortos apresentou um formato J-invertido (Fig. 7b e d). A área apre- 
Tabela 3: Índice de similaridade de Sørensen (qualitativo, variando de 0 a 1) para a flora lenhosa das cinco parcelas de cerrado denso amostradas na Reserva Ecológica do IBGE - RECOR, Distrito Federal, considerando os indivíduos a partir de $5 \mathrm{~cm}$ de diâmetro a $30 \mathrm{~cm}$ de altura do solo.

\begin{tabular}{lccccc}
\hline & Parcela 361 & Parcela 363 & Parcela 365 & Parcela 372 & Parcela 374 \\
\hline Parcela 361 & 1 & 0,7632 & 0,6988 & 0,6944 & 0,6316 \\
Parcela 363 & 0,7632 & 1 & 0,7470 & 0,7222 & 0,7105 \\
Parcela 365 & 0,6988 & 0,7470 & 1 & 0,7089 & 0,6747 \\
Parcela 372 & 0,6944 & 0,7222 & 0,7089 & 1 & 0,6381 \\
Parcela 374 & 0,6316 & 0,7105 & 0,6747 & 0,6389 & 1 \\
\hline
\end{tabular}

senta principalmente indivíduos jovens, já que 90\% dos indivíduos vivos apresentam diâmetro máximo de $13 \mathrm{~cm}$ e altura de $5 \mathrm{~m}$, enquanto que o diâmetro e altura máximos encontrados para a comunidade foram $44,9 \mathrm{~cm}$ e 9,4m (Fig. 7c e d). Cerca de $40 \%$ dos indivíduos mortos se encontram na $2^{\text {a }}$ classe de altura $(2,3$ a $3,6 \mathrm{~m})$ e cerca de $50 \%$ dos mesmos, na $1^{\text {a }}$ classe de diâmetro $(5,2$ a $9,0 \mathrm{~cm})$ (Fig. 7a e b). Assim, sugere-se que, de maneira geral, a mortalidade seja maior também para os indivíduos mais jovens.

Similaridade - a similaridade florística foi alta na comparação entre as parcelas de cerrado denso, uma vez que os valores obtidos para o coeficiente de Sørensen foram próximos de 1 (de acordo com Gauch 1982, uma similaridade maior que 0,5 já é considerada alta) (Tab. 3). Tal similaridade pode ser explicada pela homogeneidade edáfica (latossolo vermelhoescuro) e topográfica do bloco de 10 ha onde estas parcelas foram estabelecidas. Resulta- dos similares foram obtidos em trabalhos com metodologia similar em diferentes áreas do Distrito Federal (Felfili et al. 1994; Filgueiras et al. 1998).

Quando foi considerada a densidade das espécies pelo índice de Czekanowski (Kent \& Coker 1994), a similaridade ainda continuou alta, com exceção da comparação entre as parcelas 361 e 365 (47\%) (Tab. 4). Ou seja, a estrutura da comunidade é um fator diferenciador como já constatado por Felfili et al. (1997, 1998). Apesar da similaridade específica elevada, a densidade entre algumas parcelas variou mais acentuadamente. Classificação - na classificação pelo método TWINSPAN com relação às parcelas, não se obteve divisões significativas que separassem as mesmas em grupos com composição de espécies similar e diferenciados entre si. Dessa forma, confirma-se a alta similaridade entre as parcelas demonstrada pelo coeficiente de Sørensen. Entretanto, para

Tabela 4: Índice de similaridade de Czezanowski (quantitativo, dado em porcentagem) para a flora lenhosa das cinco parcelas de cerrado denso amostradas na Reserva Ecológica do IBGE - RECOR, Distrito Federal, considerando os indivíduos a partir de $5 \mathrm{~cm}$ de diâmetro a $30 \mathrm{~cm}$ de altura do solo.

\begin{tabular}{lccccc}
\hline & Parcela 361 & Parcela 363 & Parcela 365 & Parcela 372 & Parcela 374 \\
\hline Parcela 361 & 100,00 & 55,63 & 47,06 & 54,65 & 57,22 \\
Parcela 363 & 55,63 & 100,00 & 60,17 & 53,07 & 68,75 \\
Parcela 365 & 47,06 & 60,17 & 100,00 & 50,78 & 59,80 \\
Parcela 372 & 54,65 & 53,07 & 50,78 & 100,00 & 53,29 \\
Parcela 374 & 57,22 & 68,75 & 59,80 & 53,29 & 100,00 \\
\hline
\end{tabular}



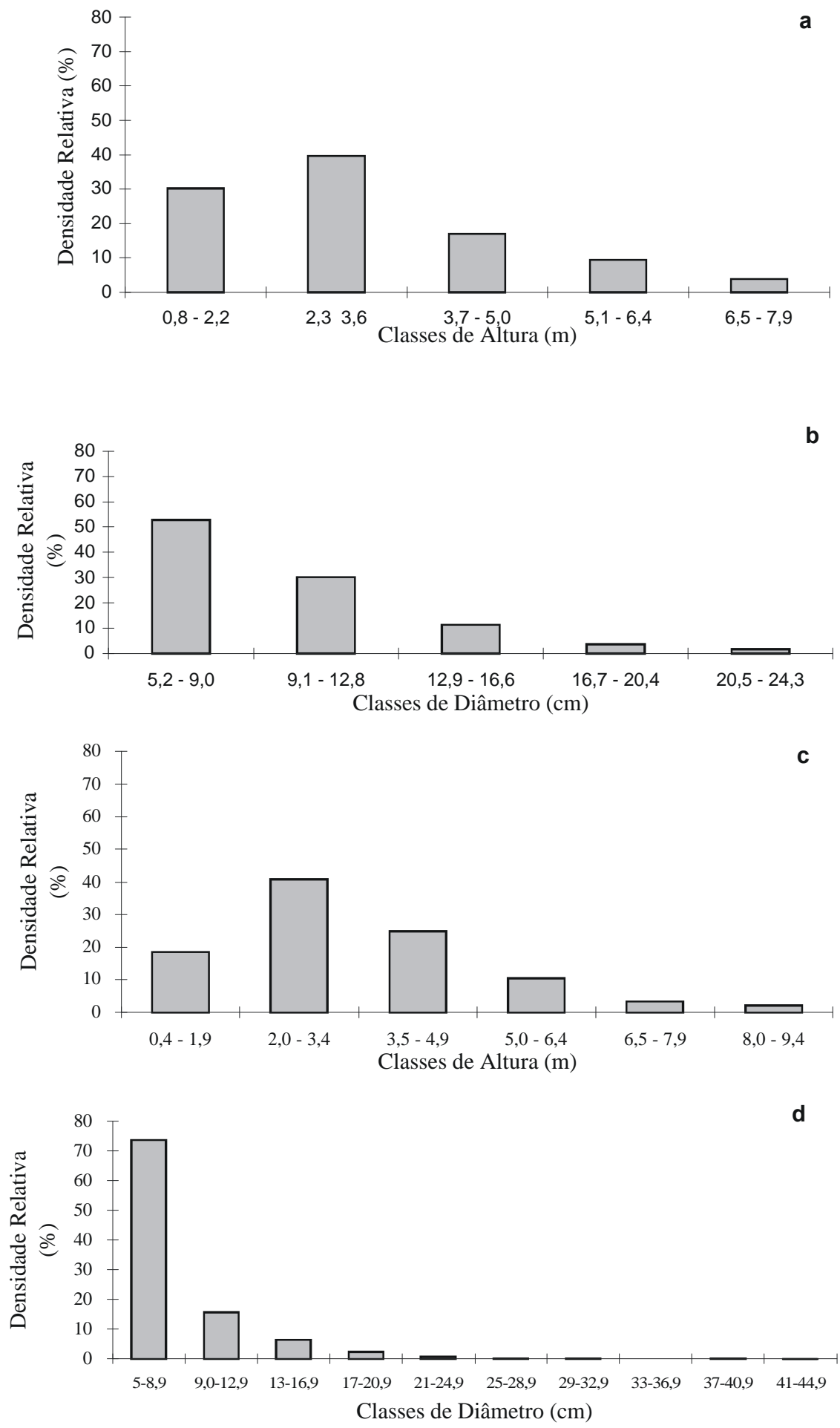

Figura 7. Distribuição em classes de altura e diâmetro dos indivíduos mortos (a) e (b) e vivos (c) e (d) amostrados na Reserva Ecológica do IBGE - RECOR, Distrito Federal. 
espécies, foi possível obter uma separação das mesmas, considerando-se a primeira e a segunda divisões, em quatro grupos de espécies (Fig. 8). Os autovalores (EIGENvalues) foram superiores a 0,30 indicando uma divisão forte (Kent \& Coker 1992). Apesar de se observar uma homogeneidade entre as parcelas, em uma escala menor, podese verificar um agrupamento preferencial de certas espécies, ou seja, as espécies apresentam-se fortemente associadas. Os determinantes destas associações tanto podem ser bióticos como abióticos ou mesmo interações entre estes fatores. Recomendase estudos que investiguem as relações da vegetação com o ambiente neste cerrado.

\section{Agradecimentos}

Os autores agradecem à Prof ${ }^{\mathrm{a}}$. Dra Heloísa S. Miranda e ao Prof. Dr. Bráulio Dias, do Departamento de Ecologia da Universidade de Brasília pela concessão dos dados aqui analisados; ao CNPq e CAPES pelo apoio financeiro. A RECOR-IBGE está reconhecida como um site do programa PELD (Pesquisa Ecológica de Longa Duração).

\section{Referências Bibliográficas}

Alho, C.J.R. \& Martins, E.S. 1995. De Grão em Grão, o Cerrado Perde Espaço (Cerrado - Impactos do Processo de Ocupação). WWF- Fundo Mundial para a Natureza. Brasília.

Dias, B.F. de S. 1994. A conservação da natureza. Pp.607-663. In: M. N. Pinto (Org.). Cerrado: Caracterização, Ocupação e Perspectivas. Editora Universidade de Brasília. Brasília.

Eiten, G. 1994. Vegetação do Cerrado. Pp. 17-73. In: M. N. Pinto (Org.). Cerrado: Caracterização, Ocupação e Perspectivas. Editora Universidade de Brasília. Brasília.

Felfili, J. M. 1994. Floristic composition and phytosociology of the gallery forest alongside the Gama stream in Brasília, DF, Brazil. Revista Brasileira de Botânica. 17(1):1-11
Felfili, J. M. 1995. Diversity, structure and dynamics of a gallery forest in central Brazil. Vegetatio 117:1-15.

Felfili, J. M. \& Silva-Jr, M. C. 1992. Floristic composition, phytosociology and comparison of cerrado and gallery forests at Fazenda Água Limpa, Federal District, Brazil. Pp: 393-407. In: P.A. Furley; J. Proctor, J.A. Ratter (Eds.) Nature and Dynamics of Forest-Savanna Boundaries. Chapman \& Hall. London.

Felfili, J. M.; Silva Jr., M.C.; Rezende, A.V.; Machado, J.W.B.; Walter, B.M.T.; Silva, P.E.N. \& Hay, J.D. 1993. Análise comparativa da florística e fitossociologia da vegetação arbórea do cerrado sensu stricto na Chapada Pratinha, DF-Brasil. Acta Botanica Brasilica 6(2): 27-46.

Felfili, J. M. \& Silva-Jr, M. C. 1993. A comparative study of cerrado (sensu stricto) vegetation in Central Brazil. Journal of Tropical Ecology 9:277-289.

Felfili, J.M.; Filgueiras, T.S.; Haridasan, M.; Silva-Jr, M.C.; Mendonça, R.C. \& Rezende, A.V. 1994. Projeto biogeografia do bioma cerrado: vegetação e solos. Cadernos de Geociências 12 (4): 75-166.

Felfili, J. M.; Silva Jr., M.C.; Rezende, A.V.; Nogueira, P.E.; Walter, B.M.T.; Felfili, M.C.; Silva, M.A. \& Imanã Encinas, J. 1997. Comparação do Cerrado (sensu stricto) nas Chapadas Pratinha e dos Veadeiros. Pp. 6-11. In: L. L. Leite, C. H. Saito (Eds.). Contribuição ao Conhecimento Ecológico do Cerrado. Dept. Ecologia - Universidade de Brasília. Brasília.

Felfili, J.M.; Silva Jr., M.C.; Filgueiras, T.S.; Nogueira, P.E. 1998. Comparison of cerrado (sensu stricto) vegetation in Central Brazil. Ciência e Cultura 50(4): 237-243.

Filgueiras, T.S., Fagg, J.M.F.; Silva Jr, M.C.; Nogueira, P.E. 1998. Floristic and structural comparison of cerrado sensu stricto vegetation in Central Brasil. Pp. 633-647. In: F. Dallmayer, J.A. Comiskey. Forest Biodiversity in North, Central and South America, and the Caribbean. Research and Monitoring. New York: UNESO/MAB-The Parthenon Press.

Gauch, H. G. 1982. Multivariate Analysis in Community Ecology. Cambridge University Press. Cambridge.

Gentry, A.H.; Herrera-Mac Bryde, O.; Huber, O.; Nelson, B.W. \& Villamil, C.B. 1997. Regional overview: South America. Pp. 269-307. In: V.H. Heywood, S.D. Davis (Coord.). Centres of Plant Diversity. WWF/IUCN. Cambridge. 


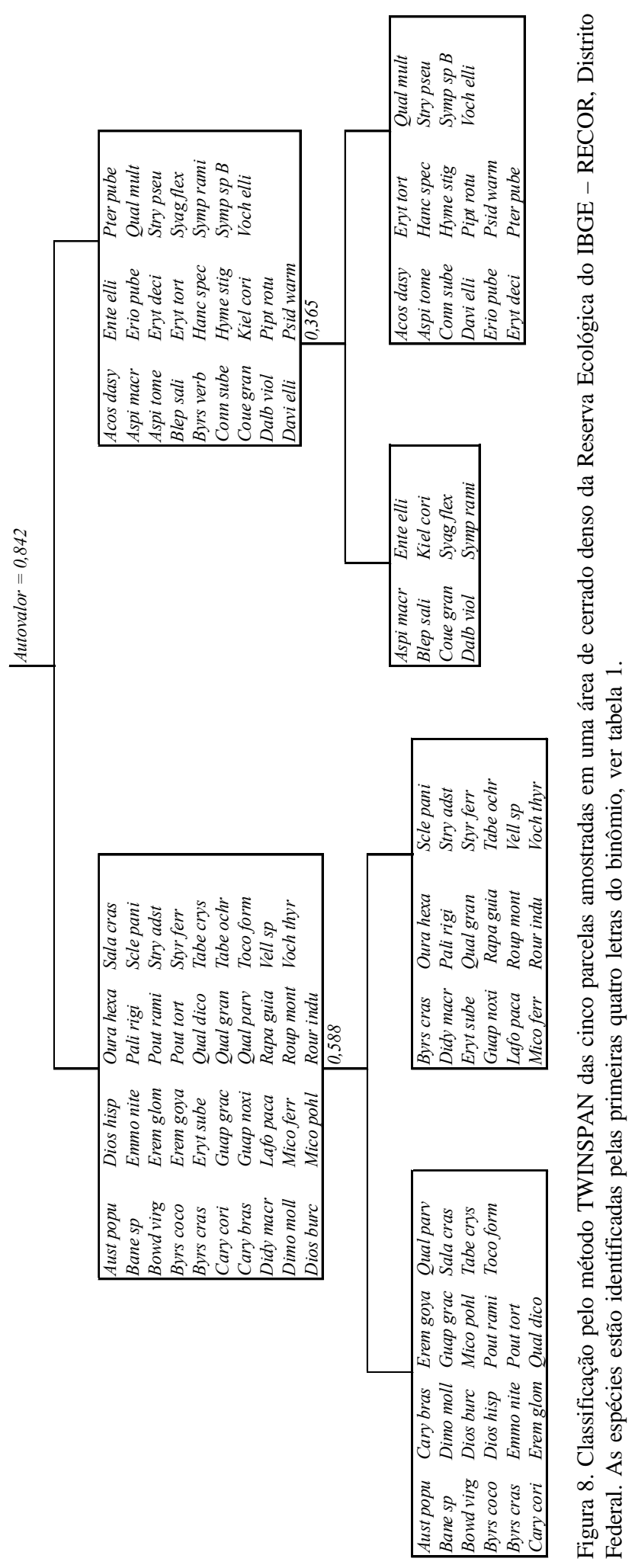


Haridasan, M. \& Araújo,G.M. 1988. Aluminiumacummulating species in two forest communities in the cerrado region of central Brazil. Forestry Ecology Management 24:15-26.

Hill, M.O. 1979. TWINSPAN - a FORTRAN program for arranging multivariate data in an ordered two-way table classification of the individuals and attributes. Cornell University. New York.

Kent, M. \& Coker, P. 1992. Vegetation Description and Analysis. Belhaven Press. London.

Kent, M. \& Coker, P. 1994. Vegetation Description and Analysis. A Practical Approach. Chichester, UK. John Willey.

Klink, C.A.; Macedo, R.F.\& Mueller, C.C. 1995. De Grão em Grão, o Cerrado Perde Espaço (Cerrado - Impactos do Processo de Ocupação). WWFFundo Mundial para a Natureza. Brasília.

Klink, C.A. 1996. Relação entre o desenvolvimento agrícola e a biodiversidade. Pp. 25-27. In: R.C. Pereira, L. C. B. Nasser (Eds.). Anais VIII Simpósio sobre o Cerrado, $1^{\text {st }}$ International Symposium on Tropical Savanas - Biodiversidade e Produção Sustentável de Alimentos e fibras nos Cerrados. Embrapa CPAC. Brasília.

Kovach, W.L. 1993. MVSP (Multivariate Statistical Package). Kovach PLC.

Margurran, A.E. 1988. Ecological Diversity and its Measurements. Croom Helm. London.

Mendonça, R.C.; Felfili, J. M.; Silva Jr., M.C.; Rezende, A.V.; Nogueira, P.E.; Walter, B.M.T. \& Filgueiras, T.S. 1998. Flora vascular do cerrado. Pp. 289-539. In: S. M. Sano, S. P. Almeida (Eds.). Cerrado: Ambiente e Flora. Embrapa CPAC. Planaltina.

Mittermeyer, R.A.; Myers, N.; Mittermeier, C.G. 1999. Hotspots Earth's Biologically Richest and Most Endagered Terrestrial Ecoregions. CEMEX Conservation International.
Mueller-Dombois, D. \& Ellemberg, H. 1974. Aims and Methods of Vegetation Ecology. John Wiley \& Sons New York..

Pereira, B.A.S.; Silva, M.A. \& Mendonça, R.C. 1993. Reserva Ecológica do IBGE, Brasília (DF): Lista das Plantas Vasculares. IBGE, Divisão de Geociências do Distrito Federal. Rio de Janeiro.

Ribeiro, J. F.; Silva, J. C. S. \& Batmanian, G. J. 1985. Fitossociologia de tipos fisionômicos de cerrado em Planaltina-DF. Revista Brasileira de Botânica 8:131-142.

Ribeiro, J. F.\& Walter, B.M.T. 1998. Fitofisionomias do bioma cerrado. Pp.89-166. In: S. M. Sano, S. P. Almeida (Eds.). Cerrado: Ambiente e Flora. Embrapa CPAC. Planaltina.

Rossi, C.V.; Silva Jr., M.C. \& Santos, C.E.N. 1998. Fitossociologia do estrato arbóreo do Cerrado (sensu stricto) no Parque Ecológico Norte, BrasíliaDF. Boletim do Herbário Ezechias Paulo Heringer 2: 49-56.

Sampaio, A.B.; Nunes, R.V. \& Walter, B.M.T. 1997. Fitossociologia de uma mata de galeria na Fazenda Sucupira do CENARGEN, Brasília-DF. Pp. 29-37. In: L. L. Leite, C. H. Saito (Eds.). Contribuição ao Conhecimento Ecológico do Cerrado. Dept. Ecologia - Universidade de Brasília. Brasília.

Sato, M.N. \& Miranda, H.S. 1996. Mortalidade de plantas lenhosas do cerrado sensu stricto submetidas a diferentes regimes de queima. Pp. 102-111. In: H.S. Miranda, C.H. Saito, B.F.S Dias (Orgs.). Impactos de Queimadas em Áreas de Cerrado e Restinga. Dept. Ecologia - Universidade de Brasília. Brasília.

Silva, A.F. \& Leitão Filho, H.F. 1982. Composição florística e estrutura de um trecho da Mata Atlântica de encosta no Município de Ubatuba (São Paulo, Brasil). Revista Brasileira de Botânica 5:43-52. 